IAC-04-IAF-448

\title{
THE ADVANCED HYPERSPECTRAL MISSION ENMAP (ENVIRONMENTAL MONITORING AND ANALYSIS PROGRAM) - GERMANY PREPARES FOR THE FUTURE
}

\author{
T. Stuffler ${ }^{(1)}$, C. Kaufmann ${ }^{(2)}$, S. Hofer ${ }^{(1)}$, H. Mehl ${ }^{(3)}$ G. Schreier ${ }^{(3)}$ \\ A. Mueller ${ }^{(3)}$, G. Arnold ${ }^{(4)}$, M. Langemann ${ }^{(5)}$, H. Bach ${ }^{(6)}$, B. Doll ${ }^{(7)}$, U. Benz ${ }^{(8)}$, R. Haydn ${ }^{(9)}$, \\ F. Jung-Rothenhäusler ${ }^{(10)}$ \\ ${ }^{(1)}$ Kayser-Threde GmbH, Wolfratshauser Str. 48, 81379 Munich, Germany \\ Email: timo.stuffler@kayser-threde.de; sh@kayser-threde.de \\ (2) Geoforschungszentrum Potsdam, Telegraphenberg, 14473 Potsdam, Germany \\ Email: charly@gfz-potsdam.de \\ ${ }^{(3)}$ DLR DFD, Oberpfaffenhofen, 82234 Wessling, Germany \\ Email: harald.mehl@dlr.de; gunter.schreier@dlr.de; andreas.mueller@dlr.de \\ (4) DLR-OS, Rutherfordstr. 2, 12489 Berlin, Germany \\ Email: gabriele.arnold@dlr.de \\ ${ }^{(5)}$ EADS Astrium GmbH, 88039 Friedrichshafen, Germany \\ Email: manfred.langemann@astrium.eads.net \\ ${ }^{(6)}$ Vista, Gabelsbergerstr. 51, 80333 München, Germany \\ Email: bach@vista-geo.de \\ (7) Spacetec GmbH, Seelbachstr. 21 \\ Email: bernhard.doll@spacetech-i.com \\ ${ }^{(8)}$ Definiens, Trappentreustr. 1, 80339 München, Germany \\ Email: ubenz@definiens.com \\ (9) GAF GMBH, Arnulfstr. 197, 80634 München, Germany \\ Email: haydn@gaf.de \\ ${ }^{(10)}$ RapidEye AG, Wolfratshauser Str. 48, 81379 München \\ Email: Rothenhauesler@Rapideye.de
}

\begin{abstract}
In the upcoming generation of satellite sensors, hyperspectral instruments will play a significant role, being considered a world-wide mapping tool within various future planning. In this context a German team is proposing the advanced hyperspectral sensor EnMAP as the next German satellite mission, scheduled for launch in 2009. The instrument performance allows for a detailed monitoring, characterisation and parameter extraction of rock/soil targets, vegetation, and inland and coastal waters on a global scale. By the scientific lead of GFZ Potsdam and the industrial prime of Kayser-Threde, the ongoing planning aims towards an internationalisation of the mission approach. A synergetic cooperation with India and/or Canada is investigated in the definition and planning phase.

The EnMAP instrument provides information based on about 200 continuous spectral bands in the wavelength range between $420-2450 \mathrm{~nm}$ with a ground sampling distance of $30 \mathrm{~m} \times 30 \mathrm{~m}$. Thus, the broad science and application community can draw from an extensive and highly resolved pool of
\end{abstract}


information supporting the modelling and optimization process on their results. Operation of an airborne system (ARES) by the research partners of the team and the evolution concerning data handling and information extraction procedures will further support this process.

The paper highlights the actual status in the planning phase (Phase A) of the EnMAP satellite and the embedding into different international hyperspectral mission scenarios. Additionally, a focus will be set on the commercialisation of the generated data products.

\section{INTRODUCTION}

The state of the Earth's environment and the growing anthropogenic impact that arise from factors such as population increase and climatic change, are the core of the justification for the Environmental Mapping and Analysis Program (EnMAP). EnMAP is directly relevant to natural and anthropogenic issues that are of immediate concern to the citizens The objectives of EnMAP are to derive relevant surface parameters on a global scale with an accuracy not achievable by currently available spaceborne sensors, to assimilate those parameters in physically based ecosystem models, and ultimately to provide information products reflecting the status of various terrestrial ecosystems.

An international team of scientific investigators and international industry partners proposes to build, launch and subsequently operate a state-ofthe-art Earth Observation (EO) satellite equipped with a spatially high-resolution Hyper-Spectral Imager (HSI).

The EnMAP satellite will be launched in 2009 , and its five-year mission will focus on issues related to the environment, agriculture, land-use, water systems, geology, and related science and applications. EnMAP's HSI will be used to identify surface cover types, and provide a quantitative assessment of molecular absorptions that are intrinsic to constituents of vegetation, soils, rocks, and water. In particular, the mission objectives are as follows:

- To provide high-spectral resolution observations of biophysical, biochemical and geochemical variables over the wavelength range from $420 \mathrm{~nm}$ to $2450 \mathrm{~nm}$ in continuous, $10-40 \mathrm{~nm}$ wide bands sampled at 5 to $20 \mathrm{~nm}$ intervals. The spatial ground sampling distance (GSD) will be 30 meters.
- To observe and develop a wide range of ecosystem parameters encompassing agriculture, forestry, soil/geological environments, and coastal zones and inland waters.

- To acquire high resolution spatial and spectral data from space that will enable/improve the retrieval of quantitative parameters needed by the users, but which are not provided by multispectral sensors.

- To provide high-quality calibrated data and information products to be used as inputs for improved modelling and understanding of biospheric/geospheric processes. This will further contribute to the assimilation of data/information into such process models.

- To develop and market high-level information products meeting the demands of stakeholders in natural resource management.

To meet these objectives, a close collaboration between scientists, value adding industry, and users will be pursued in all the development phases of EnMAP. It is planned that the further development of hyperspectral and imaging spectrometry technologies and derived products will start after Phase A using HSI data simulated from state-of-the-art hyperspectral airborne imagers such as HyMAP and ARES. This will ensure that the retrieved variables and related products from EnMAP HSI observations are of high quality, and that EnMAP will have a significant impact in many environmental disciplines.

\section{EnMAP MISSION}

The EnMAP Phase A team is formed according to the following diagram. The mission shall be executed within an international cooperation, with selected partners. The final mission scenario is being optimised within the Phase A study. 


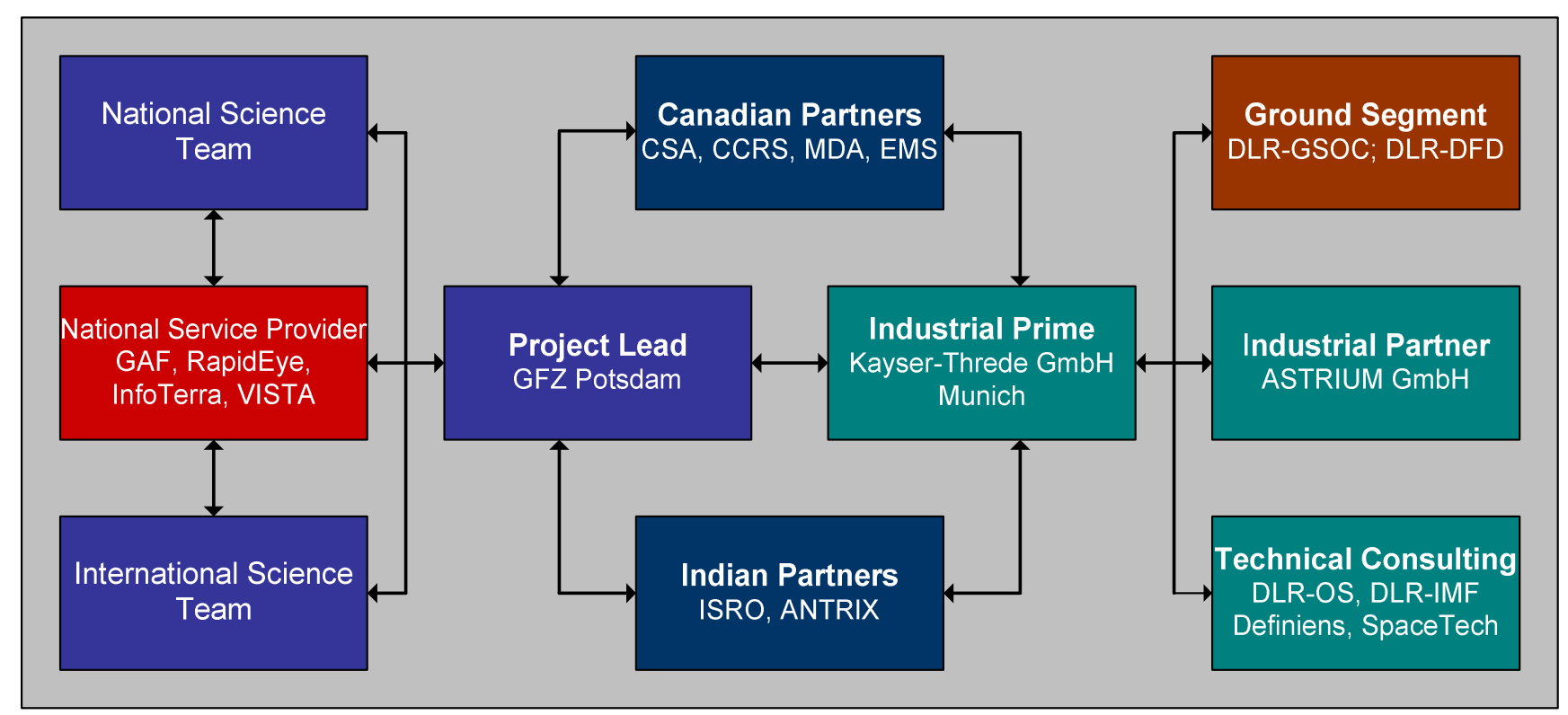

Fig. 1 EnMAP Teaming Structure

\section{The EnMAP system characteristics and mission scenario}

EnMAP represents a satellite mission with a hyperspectral instrument fulfilling the above mentioned objectives. To achieve global coverage and constant illumination conditions of the targets, a sun-synchronous orbit has been selected. A local overpass of 11:00 a.m. represents the best compromise between high radiances to achieve the required SNR and to avoid the higher cloud cover after noon. A trade-off has been performed considering the orbit height, the resulting decay rate, the swath width, and the revisit frequency to achieve the best compromise in terms of technical realisation effort and achievable data quality. This has resulted in an orbit height of about $675 \mathrm{~km}$. This already takes into account, that with a mission life time of five years and a launch in 2009, the satellite will fly towards the solar maximum. Thus, it is necessary to reduce as far as possible the impact of atmospheric drag, in order to keep the fuel required for orbit maintenance within an acceptable range. With a nominal swath width of $30 \mathrm{~km}$ at nadir and an across track pointing capability of $\pm 30^{\circ}$, the accessible target range is $\pm 390 \mathrm{~km}$. This results in a target revisit capability of roughly 3 days. A typical daily EnMAP imaging scenario, illustrating the number and sizes of the daily acquisition areas is depicted in Figure 2. The target sizes correspond to an imaging period of 3 minutes or a strip length of about $1200 \mathrm{~km}$. From the operations point of view, up to 8 stripes of EnMAP data can be collected per day, resulting in a daily data volume of about 360 Gbit (with a 2.5x lossless compression). With four contacts per day to the Neustrelitz, D and e.g. Prince Albert, CAN ground station, each with a contact duration of 7 minutes, all 200 spectral bands can be downlinked (datarate: $100 \mathrm{Mbps}$ ). The use of a 300 Mbps downlink data rate allows the acquisition on a global basis of up to 16 strips, i.e. an area of approximately $0,5 \times 10^{6} \mathrm{~km}^{2}$.

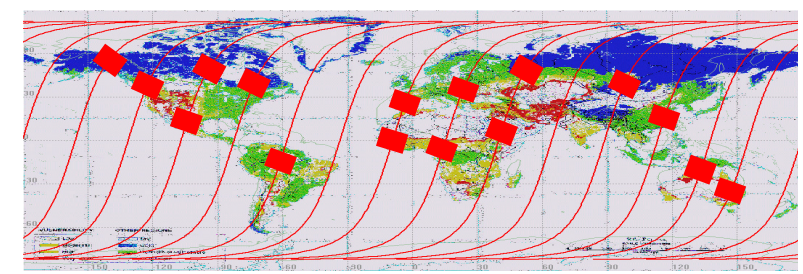

Fig. 2 Figure 2 EnMAP orbit representation showing the visibility range of Prince Albert and Neustrelitz ground stations used for data downlink and an example for a one day imaging sequence.

The EnMAP instrument characteristics are summarized in the following Table 1. 


\begin{tabular}{|c|c|c|}
\hline \multirow[t]{5}{*}{ Optics } & $\begin{array}{l}\text { Pointing } \\
\text { range }\end{array}$ & $\pm 30^{\circ}$ from nadir $( \pm 390 \mathrm{~km})$ \\
\hline & Telescope & $\begin{array}{l}\text { Effective pupil: } 270 \text { mm } \\
\text { Focal } \\
\text { length: } 810 \\
\text { mm; F\# } 1: 3 \\
\text { IFOV: } 7.63^{\prime \prime} ; \mathrm{FOV}+1.06^{\circ}\end{array}$ \\
\hline & Waveband & $\begin{array}{l}\text { VNIR: } 420-1030 \mathrm{~nm} \\
\text { ( } 92 \text { bands) } \\
\text { SWIR: } 950-2450 \mathrm{~nm} \\
\text { ( } 108 \text { bands) } \\
\text { VNIR/SWIR overlap about } 3 \text { to } \\
4 \text { bands }\end{array}$ \\
\hline & $\begin{array}{l}\text { Waveband } \\
\text { separation }\end{array}$ & $\begin{array}{l}\text { VNIR/SWIR in-field separation } \\
\text { (alternatively dichroic) }\end{array}$ \\
\hline & $\begin{array}{l}\text { Spectral } \\
\text { sampling }\end{array}$ & $\begin{array}{l}\text { VNIR: } 5 \mathrm{~nm} \text { to } 10 \mathrm{~nm} \\
\text { SWIR: } 10 \mathrm{~nm} \text { to } 20 \mathrm{~nm}\end{array}$ \\
\hline \multirow[t]{2}{*}{$\begin{array}{l}\text { Focal } \\
\text { Planes }\end{array}$} & VNIR FPA & $\begin{array}{l}\text { CCD or CMOS detector with at } \\
\text { least } 1024 \times 256 \text { pixel (EEV or } \\
\text { Fillfactory) }\end{array}$ \\
\hline & SWIR FPA & $\begin{array}{l}\text { HgCdTe hybrid CMOS detector } \\
\text { with } 1000 \times 256 \text { pixel } \\
\text { (SOFRADIR/AIM) }\end{array}$ \\
\hline \multirow{2}{*}{$\begin{array}{l}\text { Thermal } \\
\text { Design }\end{array}$} & VNIR FPA & Passive cooling \\
\hline & SWIR FPA & Active cooling \\
\hline \multirow{2}{*}{$\begin{array}{l}\text { Data Rate } \\
\text { and On- } \\
\text { Board } \\
\text { Storage } \\
\text { Capacity } \\
\end{array}$} & $\begin{array}{l}\text { Data } \\
\text { Compression }\end{array}$ & $\begin{array}{l}\mathrm{H} / \mathrm{W} \text { or } \mathrm{S} / \mathrm{W} \text { compression by } \\
\text { factor } 2.5 \text {; loss-less }\end{array}$ \\
\hline & $\begin{array}{l}\text { Onboard Data } \\
\text { Rate }\end{array}$ & $\begin{array}{l}600 \text { Mbps (=> } 240 \text { Mbps with } \\
\text { factor } 2.5 \text { compression) }\end{array}$ \\
\hline $\begin{array}{l}\text { Power } \\
\text { Consumpti } \\
\text { on }\end{array}$ & & $<120 \mathrm{~W}$ \\
\hline Mass & & $<150 \mathrm{~kg}$ \\
\hline Envelope & & $\begin{array}{l}1200 \times 700 \times 300 \mathrm{~mm} \text { incl. } \\
\text { pointing mirror }\end{array}$ \\
\hline
\end{tabular}

Table 1: EnMAP Instrument Characteristics

The Ground Control and Satellite Operation Concept

The EnMAP space segment will rely on common RF equipment (standard S- and X-Band links), and will be completely compliant with the existing German ground segment infrastructure at DLR, i.e. mission control in Oberpfaffenhofen, commanding via Weilheim, $\mathrm{D}$ and data reception via the Neustrelitz,D and other DLR X-Band ground stations.

The EnMAP operations procedures can mostly be taken from previously flown German missions such as e.g. CHAMP. In addition, it is assumed that for the launch and early orbit phase the DLR
Command Center (GSOC) will cooperate with international S-Band station operators.

The processing and archiving of the received EnMAP data will be under the responsibility of the German Remote Sensing Data Center (DFD) of DLR in Oberpfaffenhofen. The processing chain will comprise the conversion of the raw data to Level 0 and Level 1 data. The Level 1 data will be made available to participating scientists and Level $2 \mathrm{a} / \mathrm{b}$ to value-adding companies via a mission dedicated user access portal. From there, commercial customers and application projects will be served in the international context, partners such as the Canadian Centre for Remote Sensing (CCRS) have expressed its high interest in receiving the EnMAP data by using the available Canadian ground segment elements. Figure 3 shows the overall EnMAP Space and Ground Segment indicating the participation of an international partner. This cooperation will make the EnMAP data available to additional user communities. The space segment offers enough resources in terms of downlink capability and mass memory capacity to fulfil this demand. Such a cooperation will increase the throughput of the EnMAP space segment by a factor of two.

\section{Operational Hyperspectral Missions}

EnMAP is conceived as a science and research mission and a pathfinder to evolve towards an operational/commercial service. The primary and immediate targets are the science community with its specific needs for research and development and the value adding companies offering information of great interest and use by public and commercial sectors.

The value adding companies in the EnMAP team shall ensure a smooth transition between the science algorithms and the commercial exploitation. On the applications side, GAF AG and Vista contribute their long term land observation and international project experience. RapidEye $A G$ is contributing the synergy of EnMAP with RapidEye's 5 satellite constellation of high resolution, multispectral imagers (planned launch in 2007). Definiens Imaging $\mathrm{GmbH}$ shall contribute to the operationalisation of the algorithms with its award winning object oriented image analysis technology eCognition. 


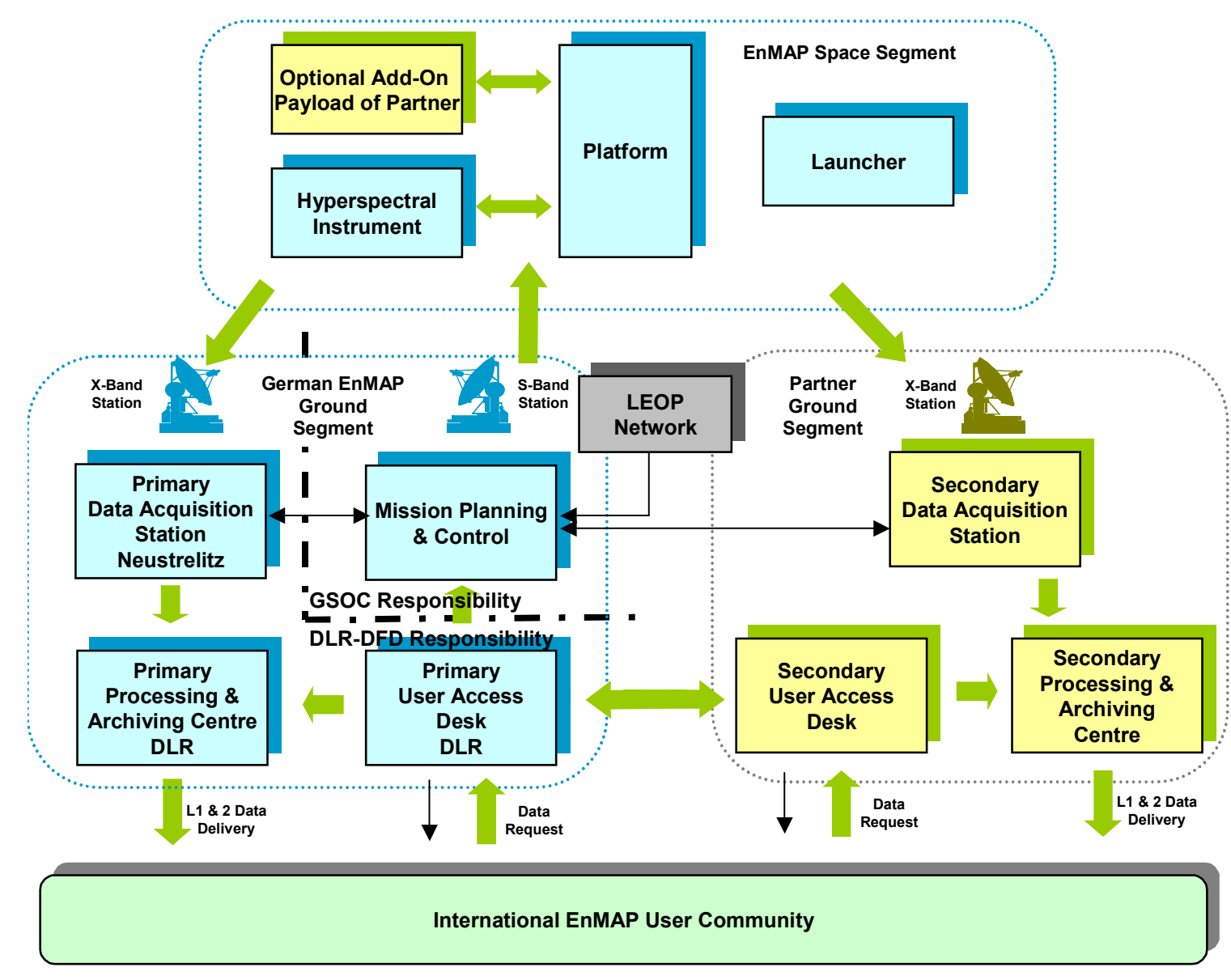

Figure 3 EnMAP Ground Segment Elements Overview

The outline of the perspectives of EnMAP for an operational and commercial service has to consider a number of critical operational factors, such as expected cost/benefit, thematic accuracy, revisit times and operationalisation of product processing. To support this approach, a preliminary assessment of operational user aspects based on existing multispectral satellite applications and airborne precursor services is executed in the Phase A.

Here, potential operational uses of EnMAP derived information, both for public and commercial users are analysed. Such an assessment encompasses a critical study of competitive factors arising from existing and planned multi/super/hyperspectral systems and alternative information sources. The tasks in Phase A also comprise a first order description and characterisation of the most important end users. The findings in the current "Global Monitoring of Environment and Security" (GMES) programme in Europe support this studies.
Several companies in Germany and elsewhere in Canada/India/Japan (GAF, Itres, Borstad \& Associates, RSI, ImageOne, NTTDate, etc.) are currently active in all the above mentioned fields of environmental applications and have active contacts to a large national and international customer base. Such value-adding companies therefore play an important role for the development of the hyperspectral commercial market. Their requirements and expectations will be assessed to obtain a sufficiently solid picture of the international market place. The anticipated use of this scenario will be illustrated by projecting the base line for a few concrete development examples from the agriculture, forestry and raw materials fields. 
EnMAP as Part of a Network for Hyperspectral $\underline{\text { Satellites }}$

In the world-wide programs for future satellite missions, hyperspectral instruments play an important role. Assuming the realization of a number of hyperspectral satellites in the time frame 2009/2010, the network enables enlarged and more continuous ground coverage. On this basis, the EnMAP team discusses in parallel different scenarios and facets of a broader international cooperation embedding the satellite in a roadmap for similar missions, a hyperspectral 'A-train'.

\section{Launch Vehicle}

A number of launchers, such as Eurockot, DNEPR, KOSMOS and PSLV are basically compatible with the EnMAP requirements and characteristics. For all launchers, the necessary $\mathrm{l} / \mathrm{Fs}$ with mission control is already established in similar missions. A detailed trade-off for the optimum launcher is performed in Phase A.

\section{CONCLUSION}

Under contract of the German Space Agency (DLR), GFZ and Kayser-Threde are performing investigations for the high performance hyperspectral mission EnMAP, scheduled for launch in 2009, the satellite is part of a roadmap for optical future hyperspectral satellites with scientific and strong operational character. EnMAP thus represents the consequent next step for Germany following the trend towards advanced future systems. Those systems are characterised delivering multiple and an enlarged information space to give value adding companies and EO product distributors an optimal basis for their activities. Additionally, the integration of EnMAP and its data into the network of future optical super- and hyperspectral missions rise the system's value by far.

Europe and especially the German space programm was pioneering in the development, operations and finally commercialisation of innovative earth observation technologies, such as Synthetic Aperture Radar (SAR). Preparing for the next generation technologies, it is obvious that the capabilities to distinguish the physical and chemical composition of materials can best be met by hyperspectral sensors. Therewith, EnMAP is setting the path for the future programmes and satellites to come.

\section{ACKNOWLEDGMENTS}

The described work is executed under DLR contract number 50EE0409.

\section{REFERENCES}

Cocks, T., Jenssen, T., Steward, A., Wilson, I. and Schields, T., 1998, The HyMap Airborne Hyperspectral Sensor: the System, Calibration, and Performance, Proc. $1^{\text {st }}$ EARSeL Workshop on Imaging Spectroscopy, M. Schaepman, D. Schläpfer, and K. Itten, eds., (Zürich).

Habermeyer, M., Strobl, P., Müller, A., 2001, Interfacing Airborne Scanner Data to a Generic Archiving and Processing Environment: A Case Study for the DAIS 7915, In: Proceedings of the Fifth International Airborne Remote Sensing Conference, San Francisco.

Hanowski, N., Faller, R., Kuch, T., 2003, MultiMission Operations of Small Science Satellites at the German Space Operations Center (GSOC), $54^{\text {th }}$ International Astronautical Congress, Sept. 29-Oct. 3, 2003 Bremen, IAF

Kiemle, S., Mikusch, E., Goehmann, M., 2001, The Product Library - A Scalable Long-Term Repository for Earth Observation Products, Data Systems in Aerospace, Nice, 2001, EUROSPACE, DASIA 2001 Data Systems in Aerospace, ESA.

Mikusch, E., Diedrich, E., Göhmann, M., Kiemle, S., Reck, C., Reißig, R., Schmidt, K., Wildegger, W., Wolfmüller, M., 2000, Data Information and Management System for the Production, Archiving and Distribution of Earth Observation Products, Data Systems in Aerospace, Montreal, 22-26 May 2000, Eurospace, DASIA 2000 - Data Systems in Aerospace, S. 401-406, ESA.

Mueller, A., Dech, S.,Habermeyer, M., Mehl, H., Richter, R., Kaufmann, H., Segl, K., Strobl, P., Haschberger, P., 2003, ARES - A new reflective / emissive imaging spectrometer for terrestrial applications, Proc. $23^{\text {rd }}$ Symposium EARSeL, Ghent, Belgium, 2 - 5 June 2003, ISBN 905966 0072

Müller, R., Lehner, M., Müller, R., Reinartz, P., Schroeder, M., Vollmer, B., 2002, A Program for Direct Georeferencing of Airborne and Spaceborne Line Scanner Images, IAPRS Vol 34, Part 1, Comm.I: 148-153, Denver. 
Richter, R. and Schlaepfer, D., 2002, Geoatmospheric processing of airborne imaging spectrometry data. Part 2: atmospheric/topographic correction, Int. J. Remote Sensing 23:2631-2649

Roth A., Eineder M., Rabus B., Mikusch E., Schättler B., 2001, SRTM/X-SAR: Products and Processing Facility, IGARSS'01, Sydney, 9.13.7.2001, IEEE, Proceedings of IGARSS'

Sümnich, K.-H., 1998, In-flight calibration of the Modular Optoelectronic Scanner (MOS), Int. J. Remote Sensing 19: 3237 - 3259.

Staenz, K. et. Al., 2004, The potential of the Canadian Hyperspectral Satellite HERO for Mine Tailings Monitoring and Assessment, ISPRS Congress, Istanbul.

\section{DEFINITIONS, ACRONYMS, ABBREVIATIONS}

\begin{tabular}{|c|c|}
\hline ARES & $\begin{array}{l}\text { Airborne Reflective and Emissive } \\
\text { Spectrometer }\end{array}$ \\
\hline CCD & Charge Coupled Device \\
\hline CCRS & $\begin{array}{l}\text { Canada Centre for Remote } \\
\text { Sensing }\end{array}$ \\
\hline CMOS & $\begin{array}{l}\text { Complementary Metal Oxide } \\
\text { Semi-conductor }\end{array}$ \\
\hline EAR & Export Administration Regulations \\
\hline EnMAP & $\begin{array}{l}\text { Environmental Mapping and } \\
\text { Analysis Program }\end{array}$ \\
\hline ENVISAT & Environmental Satellite \\
\hline EO & Earth Observation \\
\hline ESA & European Space Agency \\
\hline FPA & Focal Plane Arrays \\
\hline GAF & $\begin{array}{l}\text { Gesellschaft für Angewandte } \\
\text { Fernerkundung }\end{array}$ \\
\hline Gbit & Gigabit \\
\hline GSD & Ground Sampling Distance \\
\hline $\mathrm{HgCdTe}$ & Mercury Cadmium Telluride \\
\hline HIS & Hyperspectral Imager \\
\hline $\mathrm{H} / \mathrm{W}$ & HardWare \\
\hline HyMap & Hyperspectral Mapper \\
\hline ITAR & $\begin{array}{l}\text { International Traffic in Arms } \\
\text { Regulation }\end{array}$ \\
\hline $\mathrm{KT}$ & Kayser-Threde \\
\hline LEOP & Launch and Early Orbit Phase \\
\hline Mpbs & Mega bits per second \\
\hline PSLV & Polar Satellite Launch Vehicle \\
\hline SNR & Signal-to-Noise Ratio \\
\hline S/W & SoftWare \\
\hline SWIR & Short-Wave Infrared \\
\hline TBD & To Be Decided \\
\hline VNIR & Visible and Near Infrared \\
\hline
\end{tabular}

